\title{
REINTERPRETAR LA TRADICIÓN, TRANSFORMAR LAS PRÁCTICAS. CIENCIAS SOCIALES PARA UNA EDUCACIÓN CRÍTICA
}

Por David Parra Monserrat y Carlos Fuertes Muñoz (coords.). Valencia: Tirant Humanidades, 2019, 377 páginas. ISBN: 978-84-1606-224-9.

La monografía titulada Reinterpretar la tradición, transformar las prácticas. Ciencias Sociales para una educación crítica muestra, a partir de la participación de diferentes autores, la pluralidad de perspectivas y posiciones a la hora de tratar la Didáctica de las Ciencias Sociales. El objetivo de este libro es problematizar la tradición, reflexionar sobre la cultura canónica que se reproduce en las aulas de Ciencias Sociales y valorar el porqué del mantenimiento de ciertas prácticas, usos y representaciones de determinadas inclusiones y exclusiones. Para ello, se parte de la idea de que la Didáctica no se trata de una técnica o un conjunto de habilidades neutras, sino de una práctica cultural que no está al margen de la sociedad, la política o el poder. Por ello, uno de los retos de esta obra es que es necesario reinterpretar la tradición, la relación conocimiento-autoridad, así como los hábitos y las representaciones que condicionan la forma de ser y de actuar de los docentes.

La labor de coordinación tan necesaria en una obra de esta estructura ha sido realizada por David Parra Monserrat y Carlos Fuertes Muñoz, adscritos al Departamento de Didáctica de las Ciencias Experimentales y Sociales (Facultad de Magisterio) de la Universidad de Valencia, ambos historiadores de formación que han vinculado su carrera académica al ámbito de la Didáctica de las Ciencias Sociales. La estructura del volumen responde a la de una obra de divulgación que se articula en tres partes (con un total de trece capítulos). En la primera parte, titulada «Memoria y representación social de la Geografía y la Historia escolares», se aborda la configuración de la representación social de estas 
ciencias como materias escolares. Como han venido señalando la Historia y la Sociología crítica de la educación desde hace varias décadas, resulta fundamental entender el origen de lo que los coordinadores llaman «coherencia» de las distintas disciplinas y el modo en que éstas han dado lugar a un "paradigma pedagógico» que articula contenidos, prácticas y finalidades que acaban naturalizándose. Por ello, los cuatros primeros capítulos se relacionan con estas representaciones con la finalidad de valorar: 1) La incidencia de las memorias en su configuración; y 2) El cuestionamiento de ciertos consensos paralizantes que hacen compleja la transformación de los procesos de enseñanza-aprendizaje de las Ciencias Humanas y Sociales. El primer capítulo, realizado por Raimundo Cuesta, se titula «La venganza de la memoria y las paradojas de la historia. Leyéndome a mí mismo». Este autor tiene el objetivo de pretender huir de los prejuicios y del esquematismo que tradicionalmente alimentan los debates actuales entre los defensores y los detractores de la denominada "memoria histórica», examinando y haciendo públicas las hondas raíces intelectuales de las que se nutre la razón anamnética en tanto que crítica de la razón desde la razón. Además, Cuesta concluye que ha pretendido indagar en algunas de las fuentes históricas del pensamiento crítico, según él, factible actualmente.

En el siguiente capítulo «Tradiciones escolares en la educación geográfica. Impugnar sus rutinas para favorecer la innovación», los autores (Benito Campo, Diego García y Xosé Manuel Souto) tienen como hipótesis de trabajo que la formación inicial y continua del profesorado es la clave para poder impugnar las rutinas escolares y, en su caso, modificarlas. Para ello, se pone de manifiesto la importancia de una serie de elementos sustanciales, como son las condiciones laborales, la relación con la investigación, la organización del centro escolar, la constitución de grupos de trabajo, etc. Y se afirma que, sin el impulso inicial de la reflexión teórica sobre la práctica, es muy difícil avanzar en el campo común de la hegemonía cultural. Este capítulo, por tanto, tiene el objetivo de analizar algunas rutinas escolares que tienen sus raíces en el siglo XIX, pero que aún permanecen actualmente, y analizar algunos debates que son el resultado de la pugna entre cambios y continuidades, entre tradiciones y sueños, entre programas oficiales y propuestas de cambio, de tal manera que los recursos utilizados (TIC, salidas de campo, etc.) pueden asentar las continuidades o favorecer los cambios. Los autores 
indican que les preocupan las posibilidades y limitaciones de las salidas de campo en relación con el análisis de problemas socio-ambientales, así como con la creación de una autonomía crítica para la toma de decisiones ciudadanas, o bien, en con las metodologías didácticas que se proponen para la innovación educativa. Como conclusión, cabe destacar, entre otras, que sin una práctica teórica, la experiencia escolar de las salidas se convierte en algo muy diferente a lo programado y tan sólo mantiene el objetivo de compartir emociones ante un hecho nuevo.

El tercer capítulo de esta tercera parte, «Representación de la historia escolar y crítica del consenso del sentido común», es llevado a cabo por uno de los coordinadores de esta obra (David Parra). En él se indica que, para favorecer una transformación en el ámbito de cualquier disciplina escolar, tan importante como intentar cambiar los métodos de enseñanza-aprendizaje y las rutinas diarias del aula es comprender los mecanismos ideológicos y culturales que han conducido a determinadas representaciones que impiden avanzar en la construcción de una escuela más innovadora, más cívica y más crítica. Parra explica un proyecto didáctico titulado «Teatros de la Memoria» que se realiza en la asignatura Historia de las Ideas y del Currículum de Artes y Humanidades (Grado en Maestro en Educación Primaria de la Universidad de Valencia). El objetivo de este proyecto es, mediante simulaciones y recreaciones histórico-educativas, que los futuros maestros/as experimenten la escuela como un espacio en el que tradicionalmente se ha tendido a reproducir y reforzar determinadas rutinas y contenidos, pero también relaciones de poder, un determinado orden social y una forma de concebir la educación que ni es neutra ni universal. El autor concluye que, con la realización de pequeñas acciones basadas en prácticas contra-discursivas, en pedagogías de la representación, se puede ayudar a erosionar determinadas representaciones del profesorado.

El capítulo que cierra esta primera parte se denomina «Las representaciones de la didáctica de las ciencias sociales en los futuros docentes de educación infantil». Sus autores (Antonio José Morales y Diana Santana) analizan una experiencia que realizaron en el seno del Departamento de Didáctica de las Ciencias Experimentales y Sociales (Universidad de Valencia) con los objetivos de: 1) Fundamentar la idoneidad de plantear una propuesta didáctica para el desarrollo de la guía docente de la asignatura de Didáctica de las Ciencias Sociales en Educación Infantil 
a partir de las representaciones sociales que se derivan de los dibujos del alumnado del grado de Magisterio; 2) Analizar las representaciones sociales que sobre esta asignatura tiene el futuro profesorado de Educación Infantil, a partir de sus representaciones pictóricas; y 3) Valorar estos resultados en función de su posible incidencia en el aprendizaje de dicha asignatura. Una de las principales conclusiones a las que llegan los autores es la relevancia que asume esta asignatura para concienciar, respecto a la responsabilidad que asumen los maestros/as de Infantil, en el desarrollo de una futura ciudadanía con criterio, participativa y transformadora.

La segunda parte se titula «Materiales curriculares y pervivencia de discursos y narrativas». En ella se analiza la pervivencia de determinados lenguajes y relatos en las aulas de Geografía e Historia, especialmente en los libros de texto, y se examina la manera en que éstos se enraízan en unos imaginarios que inciden en las experiencias de vida y en las acciones cotidianas. Esta parte contiene cinco trabajos en que exploran las narrativas que se difunden en el ámbito educativo con la finalidad de valorar, entre otras cuestiones, qué clase de ciudadanía e identidades se promueven. El primer capítulo es llevado a cabo por Rafael Valls ( «Enseñanza escolar de la historia y uso de los manuales en las aulas»). Tiene el objetivo de analizar los trabajos realizados en las últimas décadas sobre el uso de los manuales escolares de Historia. Una de las preocupaciones de Valls es el uso muy mayoritario de los libros de texto convencionales y la muy escasa presencia de los materiales didácticos alternativos en las aulas. El autor pone de manifiesto que son más de un $75 \%$ los profesores y alumnos que usan los manuales escolares como su referente fundamental a la hora de desarrollar el currículum práctico en las aulas y, de ellos, más de un 50\% lo hace de una manera claramente «dependiente». Finalmente, Valls concluye que el uso de estos manuales aún sigue siendo un tema poco abordado por la investigación didáctica en comparación con otros aspectos de la manualística escolar y, por tanto, debería ser objeto de nuevas aproximaciones científicas, especialmente acudiendo al interior de las aulas. Le sigue el capítulo «Repensar la historia escolar más allá de narrativas nacionales» llevada a cabo por Jorge Sáiz. En este trabajo se presentan algunos resultados de una investigación en el que se analizan las relaciones entre educación histórica e identidad nacional española desde el ámbito valenciano. El objetivo es 
cuestionar hasta qué punto es posible, en el ámbito escolar, enseñar y aprender a pensar históricamente la identidad nacional y la historia españolas, evitando identificaciones esencialistas y comprendiendo la construcción social y cultural de las identidades. A partir del examen de relatos históricos del alumnado (E.S.O., Bachillerado y Universidad), Sáiz revela que éstos disponen de una educación histórica claramente descompensada y que en sus textos puede verificarse una mediación de la narrativa nacional española. El autor finaliza, a modo de reto futuro, afirmando la necesidad de redefinir los currículos de la historia escolar que, todavía se encuentran anclados en el relato nacional y eurocéntrico como ha constatado la Ley Orgánica para la Mejora de la Calidad Educativa (LOMCE).

El tercer capítulo de esta segunda parte es realizado por Josep R. Segarra ( $L$ La narrativa de la modernidad y el relato de nación española en los libros de texto de educación secundaria»). Segarra trata de analizar cómo la gran narrativa de la modernidad ha configurado el esquema de fondo de los manuales de Educación Secundaria en España desde los años setenta hasta la actualidad. y cómo se articula dicha narrativa con el relato de nación española que los libros de texto reproducen. El autor llega a la conclusión de que la modernidad actúa como una narrativa maestra que permea múltiples lenguajes políticos y culturales en la sociedad y que, además de su enorme capacidad para metamorfosearse ideológicamente, contribuye de manera decisiva a consolidar la "normalidad» hegemónica en nuestras democracias liberales de mercado. Finalmente, el trabajo finaliza con el reto de la necesidad de retomar la renovación educativa y (re)introducir en el aula métodos de enseñanza-aprendizaje basados en una efectiva alfabetización histórica que, a través del trabajo con fuentes primarias y secundarias, permitan a los discentes construir el conocimiento social e histórico y ayude a problematizar el presente. El siguiente capítulo es realizado por el segundo de los coordinadores de esta obra, Carlos Fuertes. El título de su trabajo es "Pervivencias en las narrativas sobre la dictadura franquista en los manuales escolares actuales». Cabe destacar que esta investigación se enmarca dentro de una investigación más amplia sobre el tratamiento educativo de la Dictadura de Franco en los libros de texto que, como afirma el autor, se trata de un «recurso hegemónico en la enseñanza de la historia» atendiendo a las ediciones adaptadas a la LOMCE. Fuertes se centra 
en los manuales de Historia de España de $2^{\circ}$ de Bachillerato, curso en el que la Dictadura Franquista recibe un tratamiento más pormenorizado y, por ello, el más pertinente para el inicio de su investigación. El autor concluye lamentándose de la pervivencia de gran parte de las problemáticas narrativas sobre el Franquismo detectadas por investigaciones precedentes sobre los manuales de la Ley General de Educación (LGE), Ley Orgánica de Ordenación General del Sistema Educativo (LOGSE) y la Ley Orgánica de Educación (LOE). Según Fuertes, a pesar de que se encuentran elementos positivos, no obstante, se trata de un «oasis» dentro de un panorama general en el que siguen predominando rasgos que, en absoluto, potencian un aprendizaje crítico y significativo de la historia del Franquismo. El último capítulo de esta segunda parte se titula «La historia de las mujeres y el derecho al pasado» y está llevado a cabo por Helena Rausell. Este trabajo analiza la ausencia de la historia de las mujeres en los manuales escolares y el discurso de las imágenes en relación con las mujeres. La autora explica que la inclusión del género femenino en el relato histórico, implica no sólo reparar una injusticia sino también, una laguna teórica. El trabajo concluye con la idea de que esta ausencia impone a hombres y mujeres referentes históricos incompletos, al tiempo que priva a todos de un mejor conocimiento del pasado.

Finalmente, la tercera y última parte de esta obra, «Formación del profesorado y transformación de la praxis educativa», tiene el objetivo de ir más allá de la tarea diagnóstica, poniendo énfasis en la formación de los docentes. Cuatro capítulos contiene esta parte en la que se plantean alternativas para que los docentes puedan contribuir a ampliar su horizonte, o a suscitar un cambio en la praxis educativa que apueste claramente por un paradigma crítico. Elvira Asensi, bajo su trabajo titulado «La investigación de las representaciones del alumnado para un aprendizaje crítico de las Ciencias Sociales: el Estado del Bienestar, un estudio de caso», tiene el objetivo de diagnosticar cuál es la visión del alumnado universitario sobre un tema de actualidad como es el caso de la construcción y vigencia del Estado del Bienestar. Todo ello, según la autora, con la intención de promover una transformación basada en una concepción crítica, ética y comprometida de la ciudadanía. Asensi llega a la conclusión de que el Estado del Bienestar se concibe mayoritariamente desde una óptica meramente materialista, en función de las ganancias económicas y en detrimento de la parte social y participativa. Es 
por ello por lo que los debates más candentes han girado en torno a la eficacia de los servicios públicos y de la justicia universal, concebida como un derecho sin condiciones o con algunas de tipo identitario o económico. La idea final de este trabajo es que con esta investigación se reflexione sobre la función social del profesorado, y sobre la manera que tienen los estudiantes universitarios de concebir el mundo que les rodea.

El segundo capítulo de esta última parte se titula «Fuentes orales en el aula de magisterio. Una experiencia: la memoria escolar». Su autor es Ricard Camil Torres y tiene por finalidad descubrir la multifactualidad documental, la realización de un proyecto mediante el recurso de entrevistas a personas de edad avanzada, con el fin de acercar a los futuros maestros la historia de la escuela, con particular atención al papel de ésta en la construcción de identidades colectivas mediante la enseñanza de las Ciencias Sociales. Tras los resultados de este proyecto, Torres llega a la conclusión de que la finalidad de implicar al alumnado en su formación cognoscitiva, reflexiva y autónoma como sujeto capaz de reflexionar científicamente de forma autónoma sobre los conocimientos, habilidades y técnicas adquiridas es la razón fundamental del planteamiento de la actividad que arroja un saldo positivo general, especialmente porque el alumnado ha sabido adaptarse a las exigencias de su primer contacto con el reto de la memoria.

En el siguiente capítulo, «Tecnología educativa y Didáctica de las Ciencias Sociales: del peso del dispositivo a la metodología como respuesta», de Juan Carlos Colomer y Juan Carlos Bel, se lleva a cabo un recorrido sobre las implicaciones de la tecnología en la materia de Ciencias Sociales con la descripción de lo que ha supuesto la inclusión de ésta (desde los manuales de texto hasta la utilización de otros recursos como el cine) para poner especial atención en los soportes digitales y en cómo estos están condicionando las prácticas docentes y el aprendizaje del alumnado. Los autores hacen hincapié en una respuesta metodológica global de inserción de la tecnología en las aulas, y se plantean una posible solución a la articulación de la tecnología educativa con la Didáctica de las Ciencias Sociales en el actual siglo XXI. Así mismo, explican que para un uso crítico de la tecnología, especialmente en Didáctica de las Ciencias Sociales, se debe avanzar promoviendo situaciones de aprendizaje que supongan a los discentes practicar los principios heurísticos de las disciplinas de la Historia y de la Geografía aprovechando las 
facilidades que ofrecen los medios digitales, de forma que el alumnado no sea un mero receptor de contenidos predefinidos. Finalmente, Colomer y Bel concluyen que esta nueva orientación necesariamente condicionará la práctica de enseñar y aprender en la actualidad. La obra finaliza con el trabajo de María Francineila Pinheiro («El prácticum en Geografía: un locus para problematizar la formación inicial docente»). Su objetivo es analizar los problemas, desafíos y sugerencias expuestas en las narrativas del alumnado y de los tutores del prácticum universitario y de la escuela (caso de estudio de la Universidad de Valencia). Tras los resultados obtenidos, la autora llega a la conclusión de que los desafíos compartidos por los tutores universitarios y de la escuela, convergen en la falta de tiempo. Esta idea es apuntada como la responsable de la falta de acompañamiento del alumnado, así como también un factor causante de la falta de aproximación y relación entre universidad y escuela. Y, por parte del alumnado, esta falta de tiempo también le supone la imposibilidad de construir un «saber docente».

Reinterpretar la tradición, transformar las prácticas. Ciencias Sociales para una educación crítica es, en suma, una obra de referencia para los estudios relacionados con la Didáctica de las Ciencias Sociales. El lector, tiene a su disposición una síntesis en la que, a partir de las contribuciones de diferentes especialistas, se remarca la relevancia de conocer y comprender el peso de las herencias en el contexto de la educación histórico-geográfica con la reflexión sobre la configuración de la representación social, especialmente de la Historia y la Geografía, como materias escolares. Destacando, que es en estas donde determinados lenguajes y relatos frecuentemente perviven en unos imaginarios que influyen en la configuración de las identidades, las experiencias y las acciones cotidianas. Con ello, las alternativas que proponen los diferentes autores que han participado pueden contribuir a ampliar el horizonte de debate, y suscitar un cambio en la praxis educativa con la apuesta de un paradigma crítico.

Álvaro Francisco Morote Seguido Universidad de Valencia alvaro.morote@uv.es 